\title{
Addendum: Protein production and purification
}

Structural Genomics Consortium, Architecture et Fonction des Macromolécules Biologiques, Berkeley Structural Genomics Center, China Structural Genomics Consortium, Integrated Center for Structure and Function Innovation, Israel Structural Proteomics Center, Joint Center for Structural Genomics, Midwest Center for Structural Genomics, New York Structural GenomiX Research Center for Structural Genomics, Northeast Structural Genomics Consortium, Oxford Protein Production Facility, Protein Sample Production Facility, Max Delbrück Center for Molecular Medicine, RIKEN Structural Genomics/Proteomics Initiative \& SPINE2-Complexes Nature Methods 5, 135-146 (2008); published online 30 January 2008; corrected after print 4 March 2008.

In the version of this Review initially published, an author (B. Martin Hallberg) was left off of the author list. This information has been added to the HTML and PDF versions of the Review. 